\title{
Factors affecting the plasma insulin concentration shortly after accidental injury in man
}

\author{
K. N. FRAYN, ${ }^{1}$ P. F. MAYCOCK, R. A. LITTLE, D. W. YATES* \& \\ H. B. STONER ${ }^{2}$
}

MRC Trauma Unit, University of Manchester, Manchester, England, and *Accident and Emergency Department, Hope Hospital, Salford, England

\section{SUMMARY}

There are conflicting reports on plasma insulin concentrations in the acutely injured. Plasma insulin and glucose concentrations have been measured in 504 patients within $8 \mathrm{~h}$ of injury, and related to the severity of injury as assessed by the injury severity score (ISS). As in previous surveys of injured patients, an extremely wide range of insulin concentrations was found $(2-141 \mathrm{mU} / \mathrm{l})$. Most of the variability occurred at lower severities of injury. In very severely injured patients (ISS $\geqslant 30$ ), insulin concentrations were uniformly suppressed $(<20 \mathrm{mU} / 1)$, especially in relation to the hyperglycaemia in these patients. Two small subgroups, patients dying within $3 \mathrm{~h}$ of injury and known psychiatric patients on psycho-active drugs, differed from the general pattern in displaying elevated insulin concentrations despite very severe injuries.

The results bear out the idea that insulin secretion is usually acutely suppressed by adrenaline after severe injury; after less severe injuries, however, the response is much less uniform.

\section{INTRODUCTION}

The hyperglycaemic reaction to stress or injury results from changes in both production and utilization of glucose (Frayn, 1982), but the hormonal mechanisms involved are not entirely clear. In particular, there are conflicting reports on the plasma insulin response to injury. In early work on the glucose intolerance in acute burn injury, it was shown

Correspondence: $\operatorname{Dr}$ R. A. Little, MRC Trauma Unit, Stopford Building, University of Manchester, Oxford Road, Manchester M13 9PT, England.

'Present address: The Sheikh Rashid Diabetes Unit, The Radcliffe Infirmary, Oxford OX2 6HE, England.

${ }^{2}$ Present address: Department of Surgery, Hope Hospital, Salford M6 8HD, England. 
that the plasma insulin response to exogenous glucose was suppressed (Allison et al.,$\frac{\mathrm{m}}{\mathrm{s}}$ 1968), and a number of studies have shown that injured patients have insuline concentrations which are generally lower than expected for their hyperglycaemia (for example, Meguid et al., 1974). However, a notable feature of most surveys of acutelye injured patients is that plasma insulin concentrations are extremely variable, ranging $\overrightarrow{\text { : }}$ from very low to very high values (Vitek et al., 1979; reviewed by Frayn, 1982). Aro understanding of the behaviour of plasma insulin after injury is important not only inc relation to control of glucose metabolism but also in connection with protein metabo $\frac{\bar{s}}{\widehat{D}}$ lism, as it has been suggested that the protein wasting observed at later stages may be

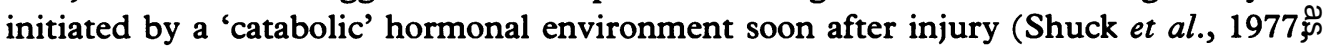
Liddell et al., 1979).

In an attempt to elucidate the factors affecting the plasma insulin concentration acutely after injury in man, the present authors have now analysed results collected from a large number of patients studied within a few hours of accidental injury. This includes results from patients reported earlier (Stoner et al., 1979). In that series however, there were insufficient numbers of severely injured patients for the pattern reported in the present work to become clear.

\section{METHOD}

As described previously (Stoner et al., 1979) venous blood samples were taken froing patients with various types of accidental injury as soon as possible after their arrivalôn the Accident and Emergency Department, and before any definitive treatment had beeno started. Only one sample was obtained from each patient. Plasma concentrations of glucose, insulin and ethanol were measured by methods described previously (Stoner $e \stackrel{?}{\longrightarrow}$ al., 1979). The patient's injuries were assessed using the injury severity score (ISS, Baker et al., 1974).

\section{Statistical methods}

Significance tests were based on non-parametric methods where possible (Siegel, 1956)غूغ except that the F-test has been used for assessing differences in variance (Snedecor 8 Cochran, 1967). Plasma concentrations of glucose and of insulin both demonstrated considerable skewness which was largely removed by conversion to logarithms and, for the calculation of variances and correlation coefficients, they have been treated as $\log$. normally distributed.

\section{RESULTS}

Five hundred and four patients (327 male), aged from 3-95 years (median: 41), with injury severity scores from $1-66$, were studied. The samples were taken within $8 \mathrm{~h}$ of. 
injury (range: $10 \mathrm{~min}-8 \mathrm{~h}$; median: $102 \mathrm{~min}$ ). Of these patients, 10 (nine male) with ISS 34-66 died within $3 \mathrm{~h}$ of injury, and 18 (14 male) with ISS 25-66 died within $24 \mathrm{~h}$.

In the group as a whole, the previous picture of great variability in plasma insulin concentrations was confirmed, with an overall range of $2-141 \mathrm{mU} / 1$. Insulin concentrations were not correlated with ISS (Kendall's rank correlation test: $P>0.05$ ) but glucose concentrations were positively related to severity $(P<0.001$ by Kendall's test).

In the very severely injured patients, insulin concentrations were mostly low, with some exceptions. Closer investigations of these exceptions showed that they all belonged to one of two small groups: those 10 patients who died within $3 \mathrm{~h}$ of injury and a group of four known psychiatric patients, on treatment with psycho-active drugs, who had all fallen from a height. These two subgroups have, therefore, been separated for further analysis.

In the remaining patients, there was a weak negative correlation between plasma insulin concentration and ISS (Fig. 1). This relationship with ISS also showed that the variability in insulin concentrations was greatest at lower severities of injury (Fig. 1).

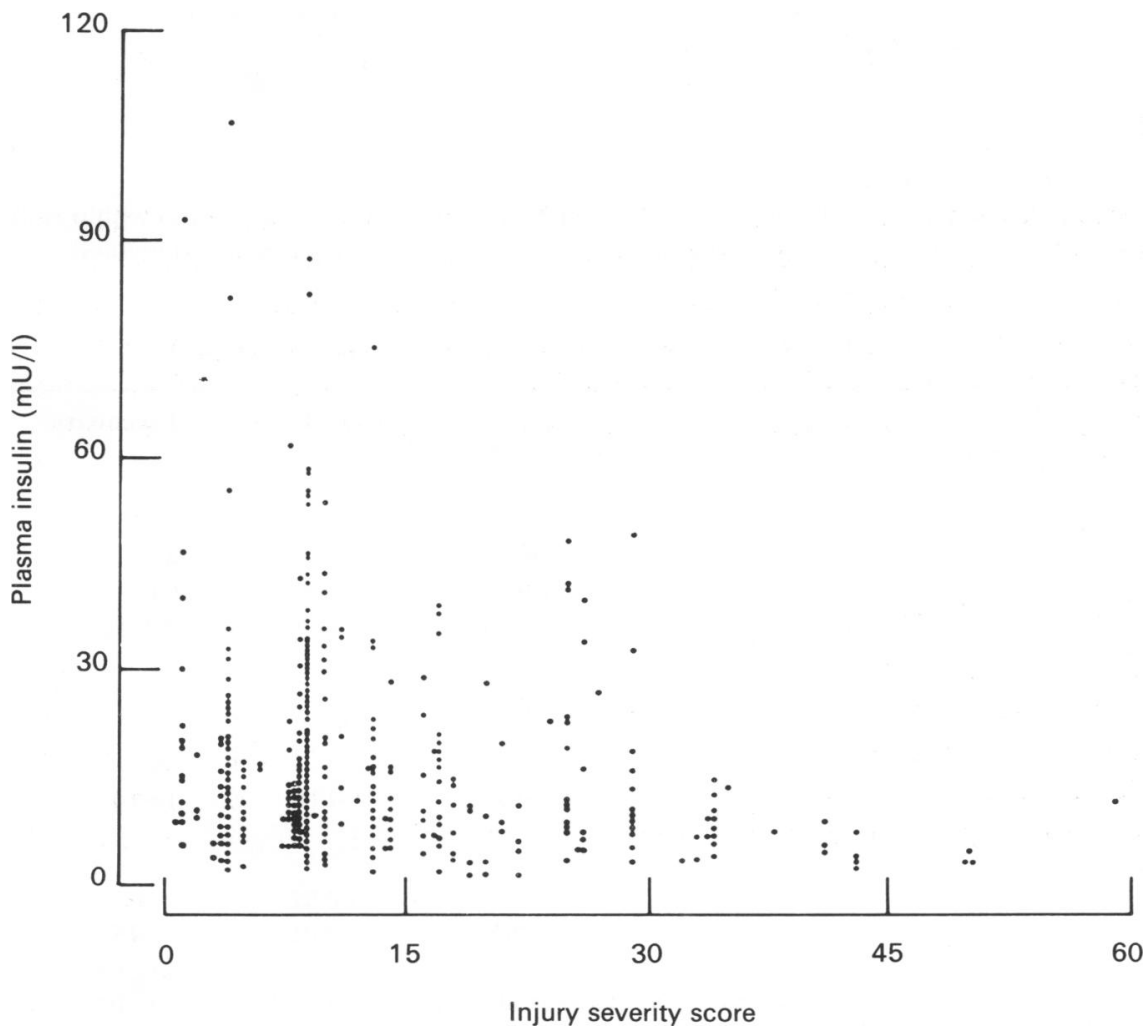

Fig. 1 Relationship between plasma insulin concentrations and severity of injury in patients studied within $8 \mathrm{~h}$ of injury. There is a significant negative relationship between insulin and ISS $(P<0.02$ by Kendall's rank correlation test; $n=477$ ). 
Table 1 Plasma glucose and insulin concentrations in recently injured patients ${ }^{1}$

\begin{tabular}{|c|c|c|c|c|}
\hline ISS range & $0-6$ & $7-12$ & $13-29$ & $\geqslant 30 \stackrel{\mathbb{D}}{\Omega}$ \\
\hline \multicolumn{5}{|c|}{ Glucose (mmol/l) } \\
\hline$n$ & 123 & 222 & 114 & 29 \\
\hline Median & $5 \cdot 4$ & $6 \cdot 0^{b}$ & $7 \cdot 3^{\mathrm{ab}}$ & $7 \cdot 9^{a}$ \\
\hline Range & $3 \cdot 4-24 \cdot 5$ & $3 \cdot 0-15 \cdot 6$ & $3 \cdot 0-14 \cdot 8$ & $3 \cdot 9-1 C$ \\
\hline \multicolumn{5}{|c|}{ Insulin $(m U / l)$} \\
\hline$n$ & 120 & 217 & 111 & 29 \\
\hline Median & 12 & 13 & 11 & $8^{\mathrm{ab}}$ \\
\hline Range & $2-107$ & $3-88$ & $2-75$ & $3-15^{\mathrm{cd}}$ \\
\hline \multicolumn{5}{|l|}{ Correlation } \\
\hline $\mathbf{r}$ & +0.27 & +0.38 & +0.25 & $-0 \cdot 19$ \\
\hline$P$ & $<0.02$ & $<0.001$ & $<0.02$ & NS \\
\hline
\end{tabular}

after injury and known psychiatric patients taking psychoactive drugs; these groups are shown in Table $2 .+\mathrm{N}$

ISS $=$ Injury severity score.

NS $=$ Not significant $(P>0.05)$.

Significance of differences between groups assessed by Wilcoxon Rank Sum test:

Difference from ISS 0-6 group: a $P<0.001$;

Difference from adjacent group to left: ${ }^{b} P<0.001$.

Significance of differences in variance by F-test on log data:

Difference from ISS $0-6$ group: $c P<0.01$;

Difference from adjacent group to left: ${ }^{\mathrm{d}} P<0.01$.

Correlation refers to the correlation between $\log$ concentrations of glucose and insulin within each groum is the correlation coefficient, $P$ the significance assessed by Kendall's rank correlation method.

Table 2 Plasma glucose and insulin concentrations in very severely injured patients ${ }^{1}$

\begin{tabular}{|c|c|c|c|}
\hline Group & $\begin{array}{l}\text { Survived } \\
(>3 \mathrm{~h})\end{array}$ & $\begin{array}{l}\text { Died } \\
(\leqslant 3 h)\end{array}$ & Psychiatric \\
\hline \multicolumn{4}{|c|}{ Glucose (mmol/l) } \\
\hline$n$ & 29 & 10 & 4 \\
\hline Median & 7.9 & $10 \cdot 4^{*}$ & $9 \cdot 0$ \\
\hline Range & $3.9-10 \cdot 9$ & $5 \cdot 9-19 \cdot 0$ & $7 \cdot 4-10 \cdot 1$ \\
\hline \multicolumn{4}{|c|}{ Insulin $(m U / l)$} \\
\hline$n$ & 29 & 10 & 4 \\
\hline Median & 8 & $15^{*}$ & $36^{*}$ \\
\hline Range & $3-15$ & $6-141$ & $10-61$ \\
\hline \multicolumn{4}{|c|}{ Correlation } \\
\hline $\mathbf{r}$ & $-0 \cdot 19$ & +0.92 & +0.74 \\
\hline$P$ & NS & $<0.01$ & NS \\
\hline
\end{tabular}

' All patients shown have an injury severity score (ISS) $\geqslant 30$. They have been divided into those dying withip $\leqslant 3$ hours of injury, known psychiatric patients on psychoactive drug treatment and other patients witlo ISS $\geqslant 30$ taken from Table 1 .

Significance of differences assessed by Wilcoxon Rank Sum test:

Difference from survivors (left hand group): ${ }^{*} P<0.01$;

Differences between centre and right-hand groups not significant. (Other notes as in Table 1.) 


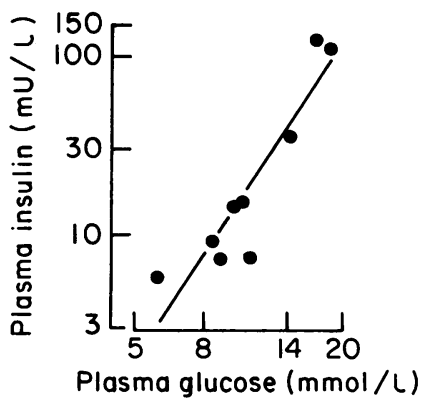

Fig. 2 Relationship between plasma concentration of glucose and insulin in patients dying within $3 \mathrm{~h}$ of injury. Both are plotted on logarithmic scales. The least mean squares regression line is shown.

Correlation coefficient $=0.92, n=10 ; P<0.01$ by Kendall's rank correlation test.

Above an ISS of 30, excluding the two subgroups described above, plasma insulin concentrations were uniformly low (all $<20 \mathrm{mU} / 1$ ), especially when considered with respect to the hyperglycaemia in these very severely injured patients (Fig. 1, Table 1). When the patients were grouped according to severity of injury (Table 1) it was clear that median plasma insulin concentrations decreased at higher ISS values, whilst plasma glucose concentrations rose with increasing ISS. Within each of these severity groups up to an ISS of 30 there was a weak but significant positive correlation between glucose and insulin concentrations, but this was lost in patients with ISS $\geqslant 30$.

In the two separate subgroups, despite injury severity scores of at least 30 in all patients, several high plasma insulin concentrations were observed (Table 2). In the case of those dying soon after injury, these were associated with very high plasma glucose concentrations (Table 2), and there was a marked positive correlation between plasma glucose and insulin concentrations within this group (Fig. 2).

The other factors considered, namely age of the patient, time after injury and the presence of an elevated plasma ethanol concentration, had relatively little effect on the plasma insulin concentration. The effect of age was assessed by comparing results in patients aged from 17-30 years with those in patients over 59 years of age, in groups divided according to ISS as in Table 1. Neither glucose nor insulin concentrations were affected by age in any group. The changes in plasma insulin and glucose concentrations with time after injury were assessed by comparing results from samples obtained within $2 \mathrm{~h}$ of injury with those obtained at or later than $2 \mathrm{~h}$, in groups divided according to ISS. Neither plasma glucose nor insulin concentrations were affected by time after injury.

Sixty-three patients had plasma ethanol concentrations above $10 \mathrm{mmol} / 1(46 \mathrm{mg} / \mathrm{dl})$. In these patients the hyperglycaemic response was reduced, as shown by a significant depression of the regression line against ISS (analysis of covariance: $P<0.01$ ). In the whole group, ethanol also depressed the plasma insulin concentration (median in ethanol-negative patients: $12.9, n=431$; in ethanol-positive patients: $9.7 \mathrm{mU} / 1, n=60$; $P<0.005$ by Wilcoxon Rank Sum test). This effect was investigated in more detail by looking at the effects of ethanol in different severity groups (Table 3) and also at different times after injury ( $<2$ or 2-8 hours). In general, in groups in which there was a significant depression of plasma insulin by ethanol, so also was there an effect on plasma 
Table 3 Effect of ethanol on plasma glucose and insulin concentrations in injured patients ${ }^{1}$

\begin{tabular}{|c|c|c|c|c|c|c|c|c|}
\hline \multirow[b]{3}{*}{ Ethanol } & \multicolumn{8}{|c|}{ ISS range } \\
\hline & \multicolumn{2}{|c|}{$0-6$} & \multicolumn{2}{|c|}{$7-12$} & \multicolumn{2}{|c|}{$13-29$} & \multicolumn{2}{|c|}{$\geqslant 30$} \\
\hline & - & + & - & + & - & + & - & + \\
\hline \multicolumn{9}{|c|}{ Glucose (immol/l) } \\
\hline$n$ & 121 & 2 & 199 & 23 & 84 & 30 & 25 & 4 \\
\hline Median & $5 \cdot 4$ & $(5 \cdot 0)$ & $6 \cdot 2$ & $5 \cdot 5^{*}$ & $7 \cdot 8$ & $6 \cdot 4^{* *}$ & $7 \cdot 9$ & $7 \cdot 3$ \\
\hline Range & $3 \cdot 4-24 \cdot 5$ & $4 \cdot 4-5 \cdot 6$ & $3 \cdot 0-15 \cdot 6$ & $3 \cdot 0-11 \cdot 2$ & $4 \cdot 2-14 \cdot 8$ & $3 \cdot 0-12 \cdot 2$ & $3.9-10.9$ & $4 \cdot 5-9 \cdot 9$ \\
\hline \multicolumn{9}{|c|}{ Insulin $(m U / l)$} \\
\hline$n$ & 118 & 2 & 196 & 21 & 82 & 29 & 25 & 4 \\
\hline Median & 12 & $(10)$ & 13 & $9 *$ & 12 & 10 & 8 & 9 \\
\hline Range & $2-107$ & $9-10$ & $4-88$ & $3-62$ & $2-75$ & $2-49$ & $3-15$ & $5-10$ \\
\hline
\end{tabular}

1 Patients dying within $3 \mathrm{~h}$ of their injuries and psychiatric patients were excluded as described in the text. Patients with a plasma ethanol concentration $>10 \mathrm{mmol} / 1$ were classified as positive. Effect of ethanol within each group assessed using Wilcoxon Rank Sum test: ${ }^{*} P<0.02 ;{ }^{* *} P<0.005$. Further subdivision according to time after injury did not affect the pattern of results.

glucose; there was no evidence for any specific depression of the plasma insuli $\vec{b}$ concentration by ethanol not mediated by a lowering of the glucose concentration. Thio relationship between the effects of ethanol and time after injury could not be invesit: gated for later times since only five patients with elevated plasma ethanol were sêc more than $3 \mathrm{~h}$ after injury.

\section{DISCUSSION}

Previous studies of the plasma insulin response to stress or injury have been conflicting Since Allison and others first observed deficient insulin secretion during operation, i myocardial infarction and in acute burn injury (Allison et al., 1967, 1968), many studieș. in experimental animals have confirmed this response to shock (for example, Cerchio $e \&$ al., 1971; Hiebert et al., 1972). However, other studies have shown insulin levels to ris $\vec{\jmath}^{3}$ with the hyperglycaemia associated with injury and to respond to glucose administra 9 tion (Vigaš et al., 1972; Frayn, 1976a). To some extent, this seems to be a species? related phenomenon; high insulin levels are observed in the dog and suppression in the monkey at similar severities of haemorrhagic shock (Hiebert et al., 1976), but ever within a species either type of response may be seen (for example, in the rat: Frayn 1976a; Turinsky et al., 1977). The wide variability of plasma insulin concentrations, seen in most studies of injured patients and confirmed here, may, therefore, represen the operation of different mechanisms in different patients.

In general, it seems that, the more severe and 'stressful' the injury, the greater th. tendency to suppress insulin secretion. In the rat, for instance, Noble Collip drumo trauma suppresses insulin secretion when administered to conscious rats (Vigaš et al $\vec{\oplus}$ 
1973), but insulin levels rise if the rats are anaesthetized when the injury is produced (Nelson \& Filkins, 1979). In rats given a full skin thickness (and, therefore, painless) dorsal scald injury under anaesthesia, insulin levels also rise (Frayn, 1976a) but restraint alone, which is a marked stressor in the rat (Kvetňanský, 1980), causes impairment of insulin secretion (Shah et al., 1977). The variability in plasma insulin concentrations seen in man at lower severities of injury may, therefore, reflect different degrees of 'stress' response, while in the very severely injured (ISS $>30$ ) the severity is such that only suppression is seen.

The suppression of plasma insulin concentrations after severe injury reflects mainly an impairment of insulin secretion (Hiebert et al., 1972). Insulin clearance is affected little (Meguid et al., 1981) if at all (Frayn, 1976b). The impairment of secretion has been shown in animal experiments to be due to an $\alpha$-adrenergic effect on the pancreas, since it is abolished by adrenal medullectomy (Vigas et al., 1973) and lessened by $\alpha$-blockade (Cerchio et al., 1973). In man, it is not possible to do a controlled trial of the effects of adrenergic blockade but the results in the four psychiatric patients were interesting in this connection. One at least of these patients was taking chlorpromazine (drug histories in the other three were unknown), a relatively strong $\alpha$-adrenergic blocker (Baldessarini, 1980), and this might account for the elevated insulin concentrations seen in this group (Table 2) despite their severe injuries. The role of adrenaline in this response to injury is also supported by the results of Frayn et al. (1985), showing that, in patients with an ISS greater than 30 , plasma adrenaline concentrations are usually above $2 \cdot 2 \mathrm{nmol} / 1$, the threshold concentration above which, in experimental work in man, plasma insulin concentrations are suppressed (Clutter et al., 1980).

The high plasma insulin concentrations seen in those patients dying soon after injury (Fig. 2) were unexpected. Although we have not measured the plasma adrenaline concentration in such patients, it seems probable that it would be high since adrenaline levels increase exponentially with increasing severity of injury (Frayn et al., 1985). Some of these patients did, however, have very high plasma glucose concentrations and the strong relationship between plasma insulin and glucose concentrations in this group (Fig. 2) suggests that the stimulus of massive hyperglycaemia was sufficient to overcome the suppression of insulin release by adrenaline. There is evidence that this can occur in man (Porte et al., 1966).

The mechanism of the elevation of plasma insulin concentrations in the less severely injured patients is less clear. In animal experiments in which this response is seen, the plasma insulin concentration rises approximately in proportion to the hyperglycaemia (Frayn, 1976a; Nelson \& Filkins, 1979). The levels reached in some patients, however, were higher than would be predicted from their hyperglycaemia. This might, perhaps, reflect stimulation by amino acids, although plasma amino acids respond little to acute injury on average (Stoner et al., 1979). It seems probable, however, that these elevated plasma insulin concentrations do not have their expected effects on metabolism. In animal experiments (Frayn, 1976a; Nelson \& Filkins, 1979) insulin resistance is seen soon after injury. In man, glucose turnover studies have not been performed at this stage after injury. Glucose tolerance and the response to exogenous insulin are, however, impaired (Thomsen, 1938; Howard, 1955; Shuck et al., 1977), and glucose oxidation reduced (Little et al., 1981), suggesting that, in man, insulin resistance may also be an early response to injury. 
Apart from the relationships with severity, this study did little to clarify other causes of variability in plasma insulin concentrations soon after injury. Age and time afte injury had little effect, although our data are not ideal for investigating the latter since্ণ in the urban environment of Salford, patients with severe injuries arrive in hospital ver. quickly. The plasma insulin concentration was depressed by ethanol in some group (Table 3) but this effect appeared to be mediated through the effect of ethanol on the plasma glucose concentration described previously after injury (Stoner et al., 1979£. rather than through any specific suppression of insulin release. This is in contrast to th observations of Vitek et al. (1982), who showed that a high ethanol concentration leads to a sustained depression of the insulin concentration in relation to that of glugose after injury. This effect was manifest at around $5 \mathrm{~h}$ after injury, however, and so we were unable to investigate it fully.

In conclusion, the results indicate that suppression of insulin secretion is seen almos invariably after very severe injuries (ISS $>30$ ). The results in the psychiatric patient疋. together with the findings of Frayn et al. (1985), support the suggestion first made bit Allison et al. (1967) that this suppression is due to a high plasma adrenaline concentrzo tion. In many patients with less severe injuries, however, high plasma insulin concen $\vec{\sigma}$ trations are seen, presumably reflecting a response to the hyperglycaemia of injury and possibly associated with insulin resistance.

\section{REFERENCES}

Allison S. P., Prowse K. \& Chamberlain M. J. (1967) Failure of insulin response to glucose load duằin operation and after myocardial infarction. Lancet $\mathbf{i}, 478-81$.

Allison S. P., Hinton P. \& Chamberlain M. J. (1968) Intravenous glucose tolerance, insulin, and free-fattyo acid levels in burned patients. Lancet ii, 1113-16.

Baker S. P., O'Neill B., Haddon W. \& Long W. B. (1974) The injury severity score: a method for describin patients with multiple injuries and evaluating emergency care. fournal of Trauma 14, 187-96.

Baldessarini R. J. (1980) Drugs and the treatment of psychiatric disorders. In The Pharmacological Basis of Therapeutics, 6th ed., A. G. Gilman, L. S. Goodman \& A. Gilman (eds), p. 403. New York, MacMilla⿳亠丷厂 Publishing.

Cerchio G. M., Moss G. S., Popovich P. A., Butler E. \& Siegel D. C. (1971) Serum insulin and growț. hormone response to hemorrhagic shock. Endocrinology 88, 138-43.

Cerchio G. M., Persico P. A. \& Jeffay H. (1973) Inhibition of insulin release during hypovolemic shock Metabolism 22, 1449-58.

Clutter W. E., Bier D. M., Shah S. D. \& Cryer P. E. (1980) Epinephrine plasma metabolic clearance rates and physiologic thresholds for metabolic and hemodynamic actions in man. fournal of Clinical Investigation 63 94-101.

Frayn K. N. (1976a) Insulin secretion after injuries of differing severity in the rat. British fournal Experimental Pathology 57, 316-20.

Frayn K. N. (1976b) Disappearance of ${ }^{125}$ I-labelled and unlabelled insulins from blood in normal and injured rats. Clinical Science and Molecular Medicine 50, 385-92.

Frayn K. N. (1982) Acute metabolic responses to trauma. In Topical Reviews in Accident Surgery, Vol. 2ి N. Tubbs \& P. S. London (eds), pp. 47-66. Bristol, John Wright.

Frayn K. N., Little R. A., Maycock P. F. \& Stoner H. B. (1985) The relationship of plasma catecholamines to acute metabolic and hormonal responses to injury in man. Circulatory Shock 16, 229-40.

Hiebert J. M., McCormick J. M. \& Egdahl R. H. (1972) Direct measurement of insulin secretory rate. Studiẹ in shocked primates and postoperative patients. Annals of Surgery 176, 296-304.

Hiebert J. M., Kieler C., Soeldner J. S. \& Egdahl R. H. (1976) Species differences in insulin secretor $\frac{0}{\mathscr{O}}$ responses during hemorrhagic shock. Surgery 79 451-5 
Howard J. M. (1955) Studies of the absorption and metabolism of glucose following injury. The systemic response to injury Annals of Surgery 141, 321-6.

Kvetňanský R. (1980) Recent progress in catecholamines under stress. In Catecholamines and Stress: Recent Advances, E. Usdin, R. Kvetňanský \& I. J. Kopin (eds), p. 8. Amsterdam, Elsevier.

Liddell M. J., Daniel A. M., MacLean L. D. \& Shizgal H. M. (1979) The role of stress hormones in the catabolic metabolism of shock. Surgery, Gynecology and Obstetrics 149, 822-30.

Little R. A., Stoner H. B. \& Frayn K. N. (1981) Substrate oxidation shortly after accidental injury in man. Clinical Science 61, 789-91.

Meguid M. M., Brennan M. F., Aoki T. T., Muller W. A., Ball M. R. \& Moore F. D. (1974) Hormonesubstrate interrelationships following trauma. Archives of Surgery 109, 776-83.

Meguid M. M., Aun F., Soeldner J. S., Albertson D. A. \& Boyden C. M. (1981) Insulin half-life in man after trauma. Surgery 89, 650-3.

Nelson K. M. \& Filkins J. P. (1979) Effect of traumatic injury on sensitivity to insulin. Circulatory Shock 6, 285-95.

Porte D., Graber A. L. Kuzuya T. \& Williams R. H. (1966) The effect of epinephrine on immunoreactive insulin levels in man. fournal of Clinical Investigation 45, 228-36.

Shah J. H., Wongsurawat N., Aran P. P., Motto G. S. \& Bowser E. N. (1977) A method for studying acute insulin secretion and glucose tolerance un unanesthetized and unrestrained rats. Diabetes 26, 1-6.

Shuck J. M., Eaton R. P., Shuck L. W., Wachtel T. L. \& Schade D. S. (1977) Dynamics of insulin and glucagon secretions in severely burned patients. Fournal of Trauma 17, 706-13.

Siegel S. (1956) Nonparametric Statistics for the Behavioral Sciences. Tokyo, McGraw-Hill Kogakusha.

Snedecor G. W. \& Cochran W. G. (1967) Statistical Methods, 6th ed. Ames, Iowa State University Press.

Stoner H. B., Frayn K. N., Barton R. N., Threlfall C. J. \& Little R. A. (1979) The relationships between plasma substrates and hormones, and the severity of injury in 277 recently injured patients. Clinical Science 56, 563-73.

Thomsen V. (1938) Studies of trauma and carbohydrate metabolism with special reference to the existence of traumatic diabetes. Acta Medica Scandinavica, Supplement 91.

Turinsky J., Saba T. M., Scovill W. A. \& Chesnut T. (1977) Dynamics of insulin secretion and resistance after burns. Fournal of Trauma 17, 344-50.

Vigaš M., Haist R. E., Bauer F. \& Drucker W. R. (1972) Insulin secretion during hemorrhagic shock in dogs. Endocrinologia Experimentalis 6, 231-7.

Vigaš M., Nèmeth S. \& Jurčovič vá J. (1973) The mechanism of trauma induced inhibition of insulin release. Hormone and Metabolic Research 5, 322-4.

Vitek V., Lang D. J. \& Cowley R. A. (1979) Admission serum insulin and glucose levels in 247 accident victims. Clinica Chimica Acta 95, 93-104.

Vitek V., Lang D. J. \& Cowley R. A. (1982) Aggravating effect of alcohol on admission serum insulin patterns of patients with trauma and in a state of shock. Surgery, Gynecology and Obstetrics 154, 326-32.

Received 1 September 1986; accepted 10 October 1986 